\title{
Avaliação cromatográfica de compostos voláteis de cachaças produzidas com leveduras de diferentes procedências
}

\author{
Chromatographic evaluation of volatile compounds in brazilian \\ sugar cane spirits produced with yeasts from different locations
}

\author{
Paulo Henrique Alves da SILVA ${ }^{1 *}$, Juliana de Oliveira SANTOS ${ }^{1}$, Leandro Dias ARAÚJO', \\ Fernanda Carolina FARIA ${ }^{1}$, Alexandre Fontes PEREIRA ${ }^{1}$, Valdinéia Aparecida DE OLIVEIRA ${ }^{2}$, \\ Maristela de Araújo VICENTE2, Rogélio Lopes BRANDÃO²
}

\begin{abstract}
Resumo
Procurou-se neste trabalho produzir cachaças em escala de laboratório a partir de leveduras isoladas de alambiques de diferentes regiões de Minas Gerais, avaliando-se e comparando-se a composição química destas em relação a cachaças de marcas comerciais. Os alambiques selecionados para isolamento das leveduras produzem tradicionalmente cachaças com características artesanais, cujos procedimentos as diferenciam sensorial e quimicamente das cachaças industriais. Avaliou-se a cinética de algumas das fermentações com relação ao teor alcoólico e à acidez produzidos durante a fermentação e alguns mostos atingiram concentrações de etanol da ordem de $9{ }^{\circ} \mathrm{GL}$ e acidez de $55 \mathrm{mg} .100 \mathrm{~mL}^{-1}$. Os compostos avaliados por cromatografia gasosa foram acetaldeído, acetato de etila, metanol, 1-propanol, álcool isobutílico, álcool isoamílico, furfural e ácido acético. As concentrações mais elevadas foram de alcoóis superiores totais, preponderando o álcool isoamílico, e de ácido acético. A composição mostrou-se bastante variável (40,59 a 671,86 mg de ácido acético.100 $\mathrm{mL}^{-1}$ de álcool anidro e 20,68 a 178,6 mg de acetaldeído.100 $\mathrm{mL}^{-1}$ de álcool anidro), e foi contrastada com os limites legais estabelecidos pela legislação brasileira (Instrução Normativa no 13, de 30/06/2005, do Ministério da Agricultura, Pecuária e Abastecimento).

Palavras-chave: leveduras; cachaça; compostos secundários; cromatografia gasosa.
\end{abstract}

\begin{abstract}
The aim of this study was to produce Brazilian sugar cane spirits (cachaça) in a laboratory scale using yeasts isolated from distilleries of different regions in Minas Gerais state evaluating and comparing their chemical composition to those of commercial brands of cachaça. The selected distilleries are from the segment of cachaça artisanal production, which includes different sensorial and chemical procedures from the ones produced in an industrial scale. Some kinetic processes were evaluated analyzing the alcoholic content and acidity produced during fermentation. Some fermenting musts showed $9^{\circ} \mathrm{GL}$ of ethanol and $55 \mathrm{mg} .100 \mathrm{~mL}^{-1}$ of acidity. The compounds analyzed by gas chromatography were acetaldehyde, ethyl acetate, methanol, 1-propanol, isobutyl alcohol, isoamyl alcohol, furfural, and acetic acid. The concentration of the total higher alcohols were the greatest, mainly the isoamyl alcohol (the, highest) and acetic acid. The chemical profiles of the cachaças varied considerably (40,59 to $671,86 \mathrm{mg}$ of acetic acid.100 $\mathrm{mL}^{-1}$ anhydrous alcohol and 20,68 to $178,6 \mathrm{mg}$ of acetaldehyde.100 $\mathrm{mL}^{-1}$ anhydrous alcohol) and all compositions were contrasted with the legal standards of the Brazilian legislation.
\end{abstract}

Keywords: yeast; cachaça; secondary compounds; gas chromatography.

\section{Introdução}

Cachaça é, de acordo com a legislação brasileira, um produto com denominação típica e exclusiva da bebida produzida no Brasil, com graduação alcoólica de 38 a 48\% em volume, medida a $20{ }^{\circ} \mathrm{C}$. Deve ser obtida pela destilação do mosto fermentado de cana-de-açúcar com características sensoriais peculiares, podendo ser adicionada de açúcares até seis gramas por litro, expressos em sacarose (BRASIL, 2003).

A história da cachaça se confunde com a própria história do Brasil. Foi a primeira bebida destilada na América Latina, descoberta no século XVI, durante a implantação da indústria açucareira pelos colonizadores portugueses. Atualmente é a terceira bebida mais consumida no mundo, com cerca de 5 mil marcas, 30 mil produtores no Brasil e volume anual em torno de 1,4 bilhões de litros (ABRABE, 2007).

As cachaças artesanais são aquelas produzidas em pequenos alambiques, onde normalmente se emprega mão-de-obra familiar. A produção destas cachaças é, em geral, feita utilizando-se fermento "caipira" ou selvagem, destilado em alambiques de cobre, com separação das frações do destilado, dentre outros procedimentos, que diferenciam sensorial e quimicamente a cachaça artesanal das industriais. A produção chega a 400 milhões de litros anuais, segundo o Ministério da Agricultura (OLIVEIRA et al., 2005). Apesar de o processo fermentativo para produção desta aguar-

${ }^{1}$ Laboratório de Produção e Qualidade de Bebidas, Departamento de Tecnologia de Alimentos, Universidade Federal de Viçosa - UFV, CEP 36570-000, Viçosa - MG, Brasil, E-mail: phasilva@ufv.br

${ }^{2}$ Departamento de Farmácia, Núcleo de Pesquisas em Ciências Biológicas - NUPEB, Universidade Federal de Ouro Preto - UFOP, CEP 35400-000, Ouro Preto - MG, Brasil ${ }^{*}$ A quem a correspondência deve ser enviada 
dente, em muitos casos, ainda ser empírico, alguns trabalhos científicos já foram realizados no sentido de isolar e identificar as leveduras responsáveis por este processo. Estas são pertencentes aos seguintes espécies, como agentes fermentativos ou contaminantes: Saccharomyces cerevisiae, Rhodotorula glutinis, Candida maltosa, Kluyveromyces marxianus, Pichia heimii, Hanseniaspora uvarum, Pichia subpellculosa, Debaryomyces hansenii e Pichia methanolica (PATARO et al., 2000; PATARO et al., 1998; SCHWAN et al., 2001).

Com relação às leveduras etanologênicas, diferentes linhagens de S. cerevisiae foram encontradas em maior abundância em fermentações para produção de aguardente (MORAIS et al., 1997; SCHWAN et al., 2001) sendo, dentre outras leveduras de menor importância, as que mais se destacam pela alta produção de álcool e pela boa tolerância a concentrações elevadas de etanol.

O caldo de cana-de-açúcar é normalmente constituído de $75-82 \%$ de água, $15-24 \%$ de açúcares (sacarose, glicose e frutose), quantidades pequenas de sólidos solúveis orgânicos (proteínas, aminoácidos, gorduras, materiais corantes, etc.) e inorgânicos (PARANHOS, 1987). Apresenta $\mathrm{pH}$ que pode variar de 4,8 a 6,0, sendo em média entre 5,0 e 6,0. Estas características fazem do caldo de cana-de-açucar um meio excelente para o desenvolvimento dafermentação alcoólica.

Cachaça é composta principalmente de água e álcool em proporções variáveis e de componentes secundários em quantidades ínfimas, que conferem à bebida suas características peculiares de aroma e sabor. Estes compostos pertencem às seguintes classes: ácidos orgânicos, aldeídos, ésteres, alcoóis superiores, furfural, terpenos, lactonas, furanos, pirazinas, dentre outros (LETHTONEN; JOUNELA-ERIKSSON, 1983; NYKANEN; NYKANEN, 1983).

Em nível nacional, a cachaça deve seguir os padrões de qualidade estabelecidos pela Instrução Normativa ${ }^{\circ} 13$, de 30 de junho de 2005 (BRASIL, 2005). Este documento diferencia cachaça e aguardente, além de estabelecer os limites de cada composto significante na bebida, que estão representados na Tabela 1.

Tabela 1. Limites dos compostos secundários e contaminantes orgânicos na cachaça, em mg.100 mL $\mathrm{m}^{-1}$ de álcool anidro.

\begin{tabular}{lc}
\hline \multicolumn{1}{c}{ Composto } & $\begin{array}{c}\text { Limite } \\
\text { máximo }\end{array}$ \\
\hline Acidez volátil, expressa em ácido acético & 150 \\
Ésteres totais, expressos em acetato de etila & 200 \\
Aldeídos totais, expressos em acetaldeído & 30 \\
Somas dos alcoóis superiores: isoamílico, isobutílico e & 360 \\
1-propanol & \\
Soma de furfural e hidroximetilfurfural & 5 \\
Metanol & 20 \\
Álcool metílico (metanol) & 20 \\
Carbamato de etila & 0,15 \\
Acroleína & 5 \\
Álcool séc-butílico (2-butanol) & 10 \\
Álcool n-butílico (1-butanol) & 3 \\
\hline
\end{tabular}

Fonte: Ministério da Agricultura, Pecuária e Abastecimento. Instrução Normativa no ${ }^{13}$, de 30/06/2005.
Procurou-se, neste trabalho, produzir cachaças em escala de laboratório a partir de leveduras isoladas de alambiques de diferentes regiões de Minas Gerais, avaliando-se e comparandose a composição química destas em relação a cachaças de marcas comerciais.

\section{Material e métodos}

\subsection{Materiais experimentais utilizados}

Para a produção experimental das cachaças, utilizou-se cana-de-açúcar da variedade precoce RB855156 com teor de sólidos solúveis de $20^{\circ}$ brix, produzida na Estação Experimental de Cana-de-açúcar da Universidade Federal de Viçosa. Dentre algumas características desta variedade estão altas adaptabilidade e estabilidade, produtividade agrícola e industrial elevada, elevado teor de sacarose e resistência intermediária a doenças (PMGCA, 2007).

Utilizaram-se para a inoculação do caldo de cana 9 linhagens de leveduras, subdivididas em 2 grupos (Tabela 2), sendo 6 cepas isoladas de alambiques de diferentes regiões do Estado de Minas Gerais no ano de 2001 (Ouro Preto) e 2003 (Ouro Preto, Lavras, Perdões, Jequitinhonha e Salinas), todas fornecidas pela Universidade Federal de Ouro Preto. Foram também utilizados 3 fermentos comercias como forma de comparação de eficiência e qualidade em relação às leveduras isoladas.

Também compõem o conjunto de materiais analíticos, 2 cachaças comerciais, sendo uma classificada informalmente como industrial e outra artesanal, que corresponderão neste trabalho às amostras 10 e 11 (Bloco 3).

\subsection{Métodos}

O isolamento e caracterização bioquímica e molecular das linhagens foram realizados no Laboratório de Biologia Celular e Molecular do Departamento de Farmácia da Universidade Federal de Ouro Preto, enquanto a produção das cachaças e as análises químicas foram realizadas no Laboratório de Produção e Qualidade de Bebidas do Departamento de Tecnologia de Alimentos, da Universidade Federal de Viçosa.

\section{Procedimentos de isolamento das leveduras}

Amostras de mosto foram coletadas das dornas de fermentação dos alambiques em frascos esterilizados de $250 \mathrm{~mL}$,

Tabela 2. Caracterização dos fermentos utilizados na produção das cachaças.

\begin{tabular}{ccc}
\hline Bloco & Identificação & Origem dos fermentos utilizados \\
\hline 1 & 1 & Diferentes cidades do Estado de Minas Gerais, \\
& 2 & caracterizadas bioquímica e geneticamente. \\
& 3 & \\
& 4 & \\
& 5 & \\
& 6 & \\
2 & 7 & Fermentos adquiridos no comércio local. \\
& 8 & \\
& 9 & \\
\hline
\end{tabular}


que foram transportados em banho de gelo e analisados o mais rapidamente possível. Realizaram-se triplicatas de diluições decimais $(1: 10 ; 1: 100 ; 1: 1000)$ em água esterilizada, que foram inoculadas em meio YP contendo peptonas ( $2 \% \mathrm{p} / \mathrm{v})$, extrato de leveduras $(1 \% \mathrm{p} / \mathrm{v})$ e ágar $(2 \% \mathrm{p} / \mathrm{v})$ suplementado com sacarose $(20 \% \mathrm{p} / \mathrm{v})$ e cloranfenicol $(0,1 \% \mathrm{p} / \mathrm{v})$ ou com sacarose $(20 \% \mathrm{p} / \mathrm{v})$, etanol $(8 \% \mathrm{p} / \mathrm{v})$ e cloranfenicol $(0,1 \% \mathrm{p} / \mathrm{v})$. As placas foram incubadas a $30^{\circ} \mathrm{C}$ ou a $37^{\circ} \mathrm{C}$ por 3 dias. Estas condições especiais, como concentrações de açúcar e temperaturas elevadas, foram estabelecidas com o objetivo de simular as condições do processo de fermentação às quais as cepas de levedura são usualmente submetidas (18-22\% de sacarose, dornas de fermentação sem controle de temperatura e elevadas concentrações de etanol).

As colônias isoladas foram repicadas para meio YP contendo sacarose $(20 \% \mathrm{p} / \mathrm{v})$, etanol $(8 \% \mathrm{p} / \mathrm{v})$ e cloranfenicol $(0,1 \% \mathrm{p} / \mathrm{v})$ e as placas incubadas a $37^{\circ} \mathrm{C}$ por 3 dias. Os isolados foram primeiramente caracterizados com base nas características morfológicas e testados quanto à capacidade de crescimento em condições adversas do meio, similares àquelas durante o processo fermentativo do caldo de cana. Realizaram-se também testes bioquímicos e análises para caracterização e diferenciação genética das leveduras isoladas (resultados não apresentados).

\section{Procedimentos de propagação das leveduras}

Realizou-se, primeiramente, a repicagem dos fermentos para $150 \mathrm{~mL}$ de caldo de cana, que foi mantido a $23^{\circ} \mathrm{C}$ sob agitação constante por aproximadamente 24 horas. Transferiu-se posteriormente o caldo para $500 \mathrm{~mL}$ e em seguida para $1500 \mathrm{~mL}$, mantendo-se as mesmas condições de tempo e temperatura. $\mathrm{O}$ inóculo foi preparado em condições padronizadas para todas as culturas. A pré-cultura foi adicionada na proporção de $10 \%$ do volume subsequente. O caldo de cana-de-açúcar foi diluído para $15^{\circ}$ brix, autoclavado na primeira etapa de propagação e, posteriormente, utilizado nas fermentações em dornas de aço inoxidável AISI 444 de capacidade de $20 \mathrm{~L}$.

\section{Acompanhamento do processo fermentativo}

O acompanhamento das fermentações ocorreu com análises, em intervalos de 8 horas, dos seguintes parâmetros do mosto:

- Teor alcoólico, por medida de densidade a $20^{\circ} \mathrm{C}$ utilizando-se picnômetro (BRASIL, 2007);

- Acidez volátil, por titulação das amostras, de acordo com Lara et al. (1998).

Tanto para as análises de teor alcoólico quanto de acidez volátil, as amostras foram destiladas previamente em equipamento específico para este fim (marca Gibertini, modelo Vade 3), com funções de arraste por vapor ou aquecimento direto, dependendo da análise posterior, seguindo-se as instruções do aparelho. Estas condições de destilação prévia são recomendadas para os métodos analíticos empregados posteriormente.

\section{Destilação para obtenção da cachaça}

Ao final das fermentações, o caldo fermentado foi destilado, separando-se 3 frações de destilado (cabeça, coração e cauda), sendo as frações coletadas correspondentes a 10, 80 e 10\%, do volume de destilado estimado, respectivamente. Para cada $10 \mathrm{~L}$ de alimentação do alambique, retirou-se 1,6 $\mathrm{L}$ de destilado total. As cachaças corresponderam à fração de coração. $O$ processo de destilação foi conduzido em alambique de cobre de capacidade total de $20 \mathrm{~L}$, adquirido em região tradicional na produção deste tipo de equipamento (Itaverava, MG). A temperatura do destilador foi controlada a $90-95^{\circ} \mathrm{C}$.

\section{Análises químicas}

As 9 cachaças produzidas em laboratório e as 2 de marcas comerciais foram submetidas à identificação e quantificação dos compostos voláteis por cromatografia gasosa. $\mathrm{O}$ aparelho utilizado foi um cromatógrafo a gás, marca Shimadzu (modelo 17 A) com detector de ionização de chamas (FID). A coluna empregada foi capilar Supelco PAG ( $30 \mathrm{~m} ; 0,25 \mathrm{~mm} ; 0,25 \mu \mathrm{m})$. Foi utilizado hélio como gás de arraste, além de ar sintético e gás hidrogênio, todos com alto grau de pureza (99,99\%). As condições cromatográficas foram as seguintes: temperatura inicial de $35^{\circ} \mathrm{C}$ por 5 minutos e gradiente de $10{ }^{\circ} \mathrm{C}$ por minuto até $100{ }^{\circ} \mathrm{C}$, permanecendo nesta temperatura por 10 minutos. A temperatura do injetor foi $180^{\circ} \mathrm{C}$, do detector foi $200^{\circ} \mathrm{C}$ e a vazão do gás de arraste foi de 1 $\mathrm{mL} /$ minuto, do hidrogênio foi $20 \mathrm{~mL} /$ minuto e do ar sintético foi $175 \mathrm{~mL} /$ minuto Foi empregado "split" de 1:10.

Para a construção das curvas de calibração, foram utilizados padrões da marca Supelco, grau de cromatografia, com pureza variando de 99,8 a $99,9 \%$. Os compostos analisados pelo método de padrão externo foram acetaldeído, acetato de etila, metanol, 1-propanol, álcool isobutílico, álcool isoamílico, furfural e ácido acético. Estes compostos foram escolhidos por serem usualmente investigados em cachaça devido às suas ações toxicológicas ou organolépticas.

\section{Análise sensorial}

Com o intuito de verificar a aceitação de cachaças produzidas por diferentes leveduras, realizou-se uma avaliação global destas através de escala hedônica de 9 pontos ancorada nos extremos pelos termos "Gostei Extremamente" a "Desgostei Extremamente". Esta análise foi inserida na Análise Descritiva Quantitativa (ADQ) realizada com 19 provadores treinados, na qual se avaliaram aspectos visuais, olfativos e gustativos das cachaças, através de parâmetros e intensidades pré-definidos. Neste trabalho, são apresentados somente os resultados obtidos para o teste de aceitação das bebidas.

\section{Resultados e discussão}

\subsection{Análises durante as fermentações}

As curvas de produção de etanol e de acidez de 3 das fermentações realizadas são apresentadas nas Figuras 1 e 2 . As fermentações apresentaram elevação gradativa do teor alcoólico e, ao final da fermentação, as cepas 1 e 3 apresenta- 

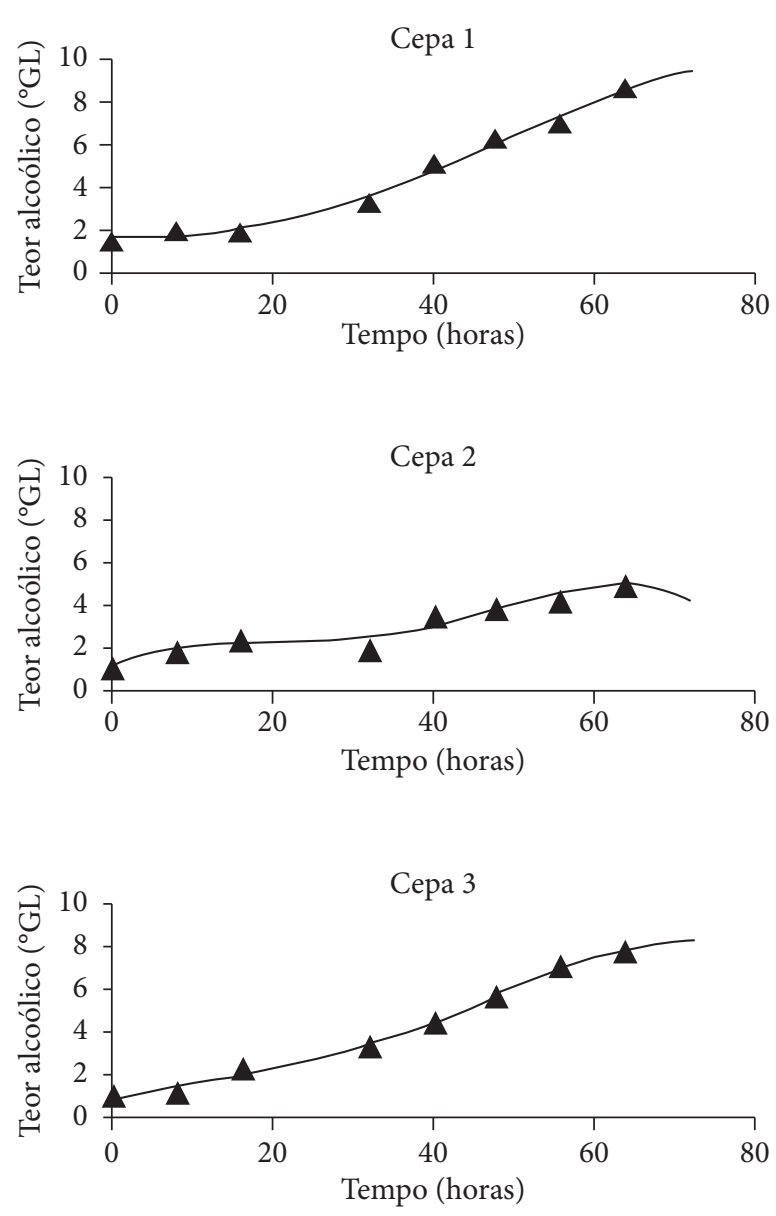

Figura 1. Resultados das análises de etanol durante a fermentação de diferentes cepas de leveduras.

ram concentrações semelhantes de etanol $\left(9,2^{\circ} \mathrm{GL}\right.$ e $8,5^{\circ} \mathrm{GL}$, respectivamente). Ocorreu uma menor produção de álcool na fermentação conduzida pela cepa 2 , indicando processo fermentativo mais lento e menos intenso. A concentração máxima de etanol produzida pela cepa 2 foi de $5,4^{\circ} \mathrm{GL}$.

Com relação à acidez, observa-se que os mostos fermentados com as cepas 1 e 3 apresentaram concentrações de ácido acético na mesma proporção ao final da fermentação $(52,2$ e $55 \mathrm{mg} .100 \mathrm{~mL}^{-1}$ de amostra).

Como foi observado na Figura 1, utilizando-se a cepa 2, a fermentação ocorreu mais lentamente, sendo que, nesta fermentação, observou-se a presença da mosca Drosophila sp., usualmente presente neste ambiente, indicadora de contaminação por bactérias acéticas. Possivelmente, na fermentação mais lenta, a presença do $\mathrm{O}_{2}$ superficial é maior, favorecendo a oxidação do etanol a ácido acético. Isto poderia explicar a elevada concentração deste composto na fermentação 2, que foi de $91,3 \mathrm{mg} .100 \mathrm{~mL}^{-1}$ de amostra.

\subsection{Composição química}

A quantificação dos compostos voláteis foi feita pelo método do padrão externo. As equações das retas obtidas para as
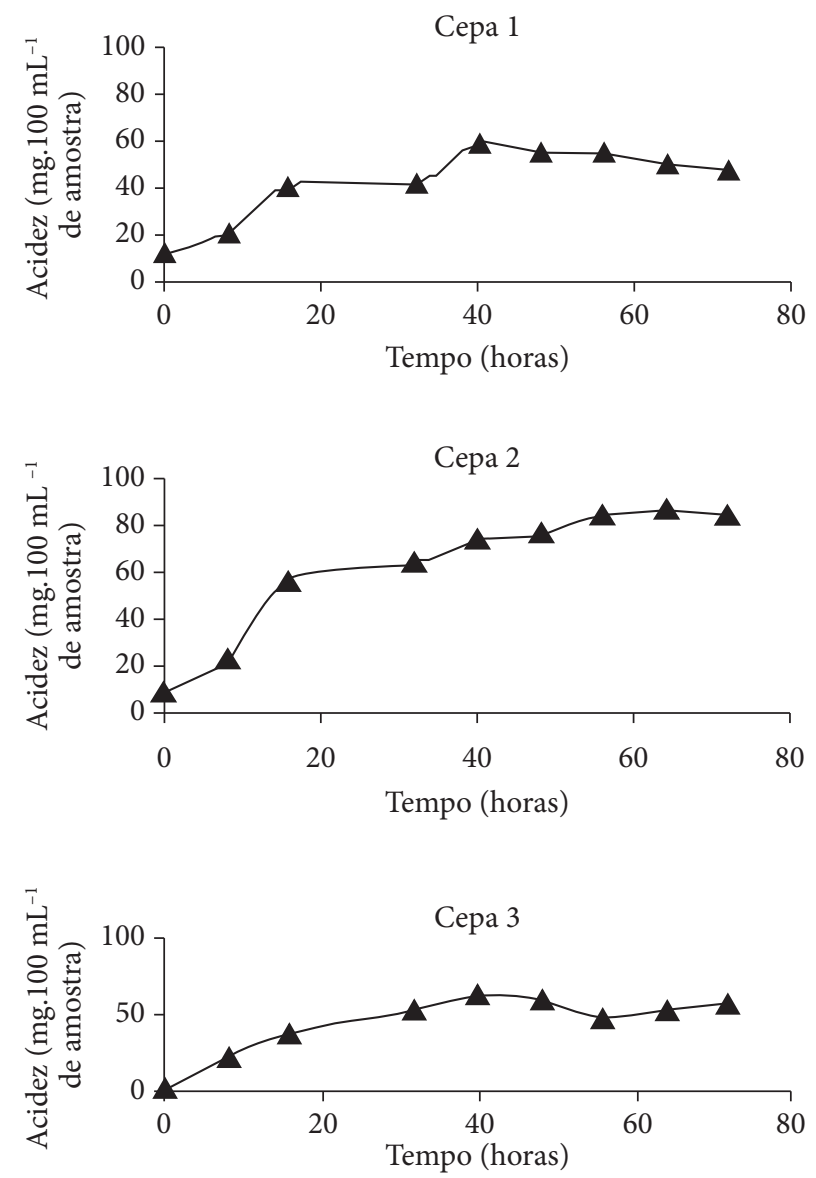

Figura 2. Resultados das análises de ácido acético durante a fermentação de diferentes cepas de leveduras.

curvas de calibração, as faixas de concentração empregadas e os respectivos coeficientes de correlação estão relacionados na Tabela 3.

Observa-se, pelos coeficientes de correlação das retas, uma boa linearidade entre a concentração do soluto e área do pico obtida na faixa de trabalho utilizada, com valores de $\mathrm{R}^{2}$ na faixa de 0,975 a 0,999 . Os resultados analíticos são apresentados na Tabela 4.

Quanto aos valores de acetaldeído, verifica-se que a amostra 1, elaborada com um dos fermentos selecionados, apresentou a maior concentração deste composto $(178,6 \mathrm{mg}$ por $100 \mathrm{~mL}$ de álcool anidro), que é bastante elevada em relação às demais amostras. Destaca-se também a amostra 9, produzida com fermento comercial, apresentando $91,42 \mathrm{mg}$ de acetaldeído por $100 \mathrm{~mL}$ de álcool anidro. Concentrações relativamente baixas foram encontradas nas 2 cachaças comerciais.

Dentre todos os compostos analisados, o acetaldeído foi o parâmetro que apresentou o maior índice de não-conformidade em relação à legislação nacional. Aproximadamente $64 \%$ das amostras superaram o valor máximo legal, de $30 \mathrm{mg}$ por $100 \mathrm{~mL}$ de álcool anidro (BRASIL, 2005). Alguns autores, investigando a presença de acetaldeído em aguardentes, não encontraram teores deste composto acima deste limite (BOGUSZ JUNIOR et al., 
2006; PINO, 1999; VARGAS; GLORIA, 1995). Estes aldeídos possuem odor penetrante e afetam o aroma das bebidas alcoólicas (NOVAES et al., 1974; POTTER, 1980).

Quanto aos ésteres, formados em reações de esterificação entre alcoóis e ácidos carboxílicos, observa-se que a maioria das amostras apresentou concentrações relativamente próximas, permanecendo na faixa de 27 a $60 \mathrm{mg} .100 \mathrm{~mL}^{-1}$ de álcool anidro e estes resultados são semelhantes aos encontrados por Murta et al. (1982). A única exceção foi a amostra 9, para a qual foi encontrada concentração de $167,83 \mathrm{mg}$ por $100 \mathrm{~mL}$ de álcool anidro, que, ainda sendo a maior de todas as amostras, não superou o limite estabelecido pela legislação brasileira, que é de $200 \mathrm{mg}$ por $100 \mathrm{~mL}$ de álcool anidro (BRASIL, 2005). Segundo Maia et al. (1991), o uso de leveduras e substratos adequados, além do monitoramento do tempo de fermentação auxiliam no controle de altas quantidades de ésteres. Baixos teores destes compostos são desejáveis, uma vez que participam de forma negativa na qualidade do produto final se em excesso (BOGUSZ JUNIOR et al., 2006).

Tabela 3. Equações da reta e valores de $\mathrm{R}^{2}$, obtidos após linearização das curvas de calibração dos compostos alvo nas faixas de concentrações citadas.

\begin{tabular}{llcc}
\hline \multicolumn{1}{c}{ Composto } & Equação da reta & $\mathrm{R}^{2}$ & $\begin{array}{c}\text { Faixas de } \\
\text { concentração } \\
\text { mg. } \mathrm{L}^{-1}\end{array}$ \\
\hline Acetaldeído & $\mathrm{Y}=5,8846 \mathrm{x}+65,799$ & 0,9949 & 15 a 600 \\
Acetato de Etila & $\mathrm{Y}=18,64 \mathrm{x}-1487,3$ & 0,9755 & 50 a 2000 \\
Metanol & $\mathrm{Y}=16,481 \mathrm{x}-92,315$ & 0,9859 & 20 a 180 \\
1-propanol & $\mathrm{Y}=34,731 \mathrm{x}-181,89$ & 0,9997 & 60 a 600 \\
Álcool Isobutílico & $\mathrm{Y}=7,861 \mathrm{x}-67,99$ & 0,9909 & 60 a 600 \\
Álcool Isoamílico & $\mathrm{Y}=43,975 \mathrm{x}-1675,7$ & 0,9978 & 60 a 1800 \\
Furfural & $\mathrm{Y}=29,244 \mathrm{x}+29,782$ & 0,9957 & 1 a 60 \\
Ácido acético & $\mathrm{Y}=12,912 \mathrm{x}-1265,9$ & 0,9963 & 150 a 1200 \\
\hline
\end{tabular}

Com relação ao metanol, considerado contaminante orgânico, destaca-se negativamente a amostra 1, que foi a única em que o limite máximo estabelecido pela legislação, de $20 \mathrm{mg} .100 \mathrm{~mL}^{-1}$ de álcool anidro, foi superado. Boscolo et al. (2000) e Bogusz Junior et al. (2006) não encontraram metanol acima deste limite em seus trabalhos, enquanto outros autores encontraram não conformidades de níveis de metanol para amostras de aguardente provenientes dos Estados da Bahia e de São Paulo (MIRANDA; DANTAS; DEL CORRAL, 1992; ZENEBON; BADOLATO; NAGTO, 1996), respectivamente. O metanol, que não é proveniente da atividade do metabolismo de S. cerevisiae, pode ser proveniente da atividade de enzimas pécticas, que atuam sobre os bagacilhos da cana, presentes no caldo devido a falhas no processo de prensa ou filtragem. Pode acontecer também a contaminação pós-fermentação e destilação, em recipientes de envase da bebida. No organismo, este composto é oxidado a ácido fórmico e posteriormente a $\mathrm{CO}_{2}$, provocando uma acidose grave (diminuição do $\mathrm{pH}$ sangüíneo), afetando o sistema respiratório, podendo levar à cegueira, ao coma e até mesmo à morte (CARDOSO et al. 1999, Windholz, 1976).

Em aguardentes, os alcoóis superiores de interesse que devem ser quantificados são: isoamílico, isobutílico e 1-propanol. A concentração do álcool 1-propanol variou de 18,32 a $75,25 \mathrm{mg}$ por $100 \mathrm{~mL}$ de álcool anidro, resultados estes que se aproximaram daqueles encontrados por Murta et al. (1982) (de 31 a $61,5 \mathrm{mg} .100 \mathrm{~mL}^{-1}$ de álcool anidro). Boscolo et al. (2000) detectou a presença de 1-propanol em 25 amostras de cachaça, encontrando valor médio de $46,0 \mathrm{mg}$ por $100 \mathrm{~mL}$ de álcool anidro. Em outros trabalhos, foram verificados resultados bastante variáveis em relação ao presente estudo, com um mínimo de 9,24 mg por $100 \mathrm{~mL}$ de álcool anidro (SOUZA e LLISTÓ, 1978) e valor máximo de $157,75 \mathrm{mg} .100 \mathrm{~mL}^{-1}$ de álcool anidro (TEJERA, 1992). Valores elevados de 1-propanol podem indicar deficiência no processo fermentativo e na obtenção do destilado alcoólico (BOGUSZ JUNIOR et al. 2006).

Tabela 4. Composição de voláteis de cachaças produzidas com diferentes tipos de leveduras.

\begin{tabular}{|c|c|c|c|c|c|c|c|c|c|c|}
\hline Bloco & Amostra & Acetaldeído & $\begin{array}{c}\text { Acetato de } \\
\text { Etila }\end{array}$ & Metanol & 1- Propanol & $\begin{array}{c}\text { Álcool } \\
\text { isobutílico }\end{array}$ & $\begin{array}{c}\text { Álcool } \\
\text { isoamílico }\end{array}$ & Furfural & $\begin{array}{l}\text { Ácido } \\
\text { acético }\end{array}$ & $\begin{array}{l}\text { Notas de } \\
\text { avaliações } \\
\text { sensoriais }\end{array}$ \\
\hline \multirow[t]{7}{*}{1} & 1 & 178,60 & 58,52 & 41,57 & 36,70 & 106,12 & 277,43 & 0,40 & 115,66 & 5,9 \\
\hline & 2 & 25,26 & 27,62 & 12,27 & 30,39 & 56,52 & 184,45 & n.d. & 68,27 & 5,1 \\
\hline & 3 & 37,73 & 30,98 & 11,44 & 39,82 & 106,59 & 376,00 & 0,32 & 67,32 & 4,9 \\
\hline & 4 & 52,35 & 38,41 & 14,62 & 18,32 & 105,53 & 328,86 & n.d. & 101,19 & 4,5 \\
\hline & 5 & 46,33 & 59,76 & 11,29 & 21,30 & 125,81 & 299,13 & 0,42 & 124,57 & 5,2 \\
\hline & 6 & 34,92 & 42,96 & 9,99 & 29,85 & 120,33 & 311,33 & n.d. & 98,28 & 5,6 \\
\hline & 7 & 20,68 & 40,38 & 6,52 & 30,24 & 52,61 & 253,10 & n.d. & 79,59 & 4,6 \\
\hline \multirow[t]{2}{*}{2} & 8 & 32,00 & 46,39 & 14,40 & 29,73 & 52,55 & 247,74 & n.d. & 74,74 & 4,8 \\
\hline & 9 & 91,42 & 167,83 & 9,64 & 21,98 & 83,77 & 203,54 & n.d. & 671,86 & 3,9 \\
\hline \multirow[t]{2}{*}{3} & 10 & 28,95 & 44,25 & 8,17 & 75,25 & 79,24 & 224,32 & 0,96 & 53,67 & 5,4 \\
\hline & 11 & 27,53 & 43,90 & 10,34 & 41,08 & 49,37 & 222,30 & 0,61 & 40,59 & 5,2 \\
\hline
\end{tabular}

Resultados em mg por $100 \mathrm{~mL}$ de álcool anidro; n.d.: não detectado; $\mathrm{e}^{\star}$ média da avaliação sensorial global por escala hedônica de nove pontos. 
O álcool isobutílico apresentou maiores concentrações nas amostras de cachaça elaboradas a partir de leveduras do bloco 1 (105 a $126 \mathrm{mg}$ por $100 \mathrm{~mL}$ de álcool anidro), enquanto concentrações mais baixas foram encontradas em cachaças nas quais utilizaram-se fermentos comerciais (bloco 2). Tejera et al. (1992) verificaram ampla faixa de concentração deste álcool em aguardentes (59,4 a 703,5 ppm), enquanto Pino (1999) relata concentração de 36,44 ppm no mesmo tipo de bebida.

Para todas as amostras, o álcool isoamílico foi encontrado em maior proporção em relação aos 3 alcoóis superiores estudados. Esta variou de 59 a $76 \%$ do somatório dos 3 compostos, compreendendo concentrações entre 184,45 e 328,86 mg por $100 \mathrm{~mL}$ de álcool anidro. Os maiores valores médios obtidos de estudo com 25 cachaças (BOSCOLO, 2000) e de bebidas provenientes do Estado do Rio Grande do Sul (BOGUSZ JUNIOR et al., 2006) foram ainda menores que a concentração mínima encontrada neste trabalho.

A legislação nacional estabelece que a soma dos alcoóis superiores citados não deve ser superior a $360 \mathrm{mg}$ por $100 \mathrm{~mL}$ de álcool anidro (BRASIL, 2005). Dentre as 11 amostras avaliadas, 6 apresentaram-se em desacordo com este padrão. A produção destes compostos deve ser controlada pelas condições do meio, entre elas, a concentração de açúcares, o pH, o conteúdo e o tipo de nitrogênio disponível, a temperatura de fermentação, a aeração e a linhagem de levedura (FICAGNA, 2005).

Outro composto analisado foi o furfural, que não foi detectado na maioria das amostras. A maior concentração foi verificada na amostra 9 (0,96 mg.100 mL de álcool anidro), mas ainda assim este valor não se aproximou do limite máximo estabelecido pela legislação, que é de 5,0 mg.100 mL $\mathrm{mL}^{-1}$ de álcool anidro (BRASIL, 2005). Para concluir sobre a conformidade das amostras, seria necessário quantificar também o hidroximetilfurfural presente nas amostras.

Dentre os produtos secundários ácidos da fermentação alcoólica, o ácido acético tem sido quantitativamente o principal, sendo expresso em acidez volátil (LIMA, 1964; NYKANEN; NYKANEN, 1983). Em relação às amostras analisadas, somente uma cachaça proveniente da fermentação do caldo de cana com levedura comercial, apresentou concentração superior ao limite máximo estabelecido pela legislação. Esta concentração (671,86 mg.100 mL $\mathrm{mL}^{-1}$ de álcool anidro) foi bastante superior às demais amostras. Com exceção da amostra citada, as concentrações se aproximaram das encontradas por Bogusz Junior et al. (2006). Nascimento et al. (1998) verificou algumas amostras fora do padrão legal para o ácido acético, mas as concentrações médias obtidas de 3 tipos de aguardentes não distanciaram dos valores das 11 amostras de cachaça deste estudo.

\subsection{Análise sensorial}

Os componentes responsáveis por aromas e sabores de alimentos e bebidas são qualificados e quantificados por análise sensorial, que é a forma científica de se avaliar a aceitação desses produtos (ISIQUE; CARDELLO; FARIA, 1998). Os resultados de aceitação se encontram em valores intermediários da escala hedônica empregada.
A maior nota foi atribuída à amostra 1, produzida por uma das leveduras isoladas de um dos alambiques de Minas Gerais. Já a aguardente 9, produzida com fermento comercial, foi a amostra menos aceita entre os provadores, permanecendo entre os julgamentos "Desgostei Ligeiramente" e "Desgostei Moderadamente”. Esta amostra apresentou níveis elevados de acetato de etila que pode conferir à bebida sabor indesejável e enjoativo (WINDHOLZ, 1976), e também de ácido acético, que afeta o sabor das cachaças, conferindo gosto ácido e sabor avinagrado.

As cachaças do bloco 1, elaboradas com fermentos provenientes de diferentes cidades de Minas Gerais, e as do bloco 3, de marcas comerciais, apresentaram em média a mesma nota de avaliação sensorial, estando compreendidas entre os conceitos "Indiferente" e "Gostei Ligeiramente". Mesmo as cachaças de marcas comerciais, amplamente distribuídas no mercado brasileiro, obtiveram notas sensoriais relativamente baixas. Ressalta-se que as cachaças produzidas em laboratório foram apresentadas aos provadores recém destiladas e mesmo as marcas comerciais não eram envelhecidas e, em geral, o hábito de consumo preferencial é por cachaças envelhecidas em tonéis de madeira.

\section{Conclusões}

Verificou-se que cachaças produzidas com diferentes leveduras e comparadas química e sensorialmente entre si e com aguardentes comerciais apresentaram concentrações bastante variáveis dos compostos analisados ao final da fermentação. Os rendimentos em etanol e a produção de ácido acético no processo fermentativo foram também bastante variáveis, demonstrando a influência de diferentes linhagens de levedura no processo fermentativo e na composição da cachaça.

Com relação aos limites máximos estabelecidos pela legislação brasileira para composição de cachaça, a maior parte das amostras apresentou não-conformidade para os teores de acetaldeído e soma de alcoóis superiores. Elevadas concentrações destes e de outros compostos podem prejudicar a qualidade sensorial do produto final.

\section{Agradecimentos}

Este trabalho foi financiado pela Fapemig - Fundação de Amparo à Pesquisa do Estado de Minas Gerais, Processo EDT2080/03. Os autores agradecem à Fundação.

\section{Referências bibliográficas}

Araras. Programa de Melhoramento Genético da Cana-de-açúcar PMGCA. Disponível em: <http://pmgca.dbv.cca.ufscar.br/htm/ catal/rb855536.php>. Acesso em: 16 Jul. 2007.

BOGUSZ JUNIOR, S. et al. Composição química da cachaça produzida na região noroeste do Rio Grande do Sul, Brasil. Ciência e Tecnologia de Alimentos, v. 26, n. 4, p. 793-798, 2006.

BOSCOLO, M. et al. Identification and dosage by HRGC of minor alcohols and esters in Brazilian sugar-cane spirit. Journal of Brazilian Chemical Society, v. 11, n. 1, p. 86-90, 2000.

BRASIL. Decreto $n^{\circ} 4851$, de 02 de outubro de 2003. Altera dispositivos do Regulamento aprovado pelo Decreto no 2.314 , de 4 de setembro 
de 1997, que dispõe sobre a padronização, a classificação, o registro, a inspeção, a produção e a fiscalização de bebidas. Diário Oficial da União, Brasília DF, 03 out. 2003, Seção 1.

BRASIL. Ministério da Agricultura, Pecuária e Abastecimento. Instrução Normativa $n^{\circ} 13$, de 30 de junho de 2005. Aprova o Regulamento Técnico para Fixação dos Padrões de Identidade e Qualidade para Aguardente de Cana e para Cachaça. Diário Oficial da União, Brasília DF, 30 jun. 2005, Seção 1.

BRASIL. Manual de Métodos de Análises de Bebidas e Vinagres. Disponível em: <http://www.agricultura.gov.br/portal/page?_ pageid=33,1040532\&_dad=portal\&_schema=PORTAL\&_ calledfrom=2>. Acesso em: 16 Jun. 2007.

CARDOSO, M. G. et al. Cachaça: Qualidade e Produção. Lavras: [s.n], 1999. (Boletim Técnico Série Extensão, v. VIII, n. 53, p. 1-26).

CARDOSO, M. G. Produção de aguardente de cana-de-açúcar. 1 ed. Lavras: Editora UFLA, 2001. 264 p.

FICAGNA, E. Influência do tempo de maceração na composição química do fermentado e do destilado de pêssego [Prunus persica (L) Batsch], Cv. Chiripá. Florianópolis, 2005. Dissertação (Mestre em Engenharia de Alimentos) - Universidade Federal de Santa Catarina - UFSC.

ISIQUE, W. D.; CARDELLO, H. M. A. B.; FARIA, J. B. Sulfur levels and acceptance of "cachaça", a Brazilian sugar cane spirit. Ciência e Tecnologia de Alimentos, v. 18, n. 3, p. 356-359, 1998.

LARA, A. B. W. H. et al. Normas analíticas do Instituto Adolfo Lutz. Métodos Químicos e Físicos para Análises de Alimentos. 3 ed. São Paulo: Instituto Adolfo Lutz, 1998.

LETHTONEN, M.; JOUNELA-ERIKSSON, P. Volatile and non-volatile compounds in the flavor of alcoholic beverages. In: PIGGOTT, J. R. Flavor of distilled beverages: Origin and Development. Flórida: Verlag Chemie International Inc., 1983. p. 64-78.

LIMA, U. A. Estudos dos principais fatores que afetam os componentes do coeficiente não alcoólico das aguardentes de cana. Piracicaba: ESALQ-USP, 1964. 141p. (Memorial de concurso para Professor Catedrático da ESALQ-USP).

MAIA, A. B. R. A. et al. Fermentação alcoólica semi-continua destinada à produção de aguardente. Boletim da Sociedade Brasileira de Ciência e Tecnologia de Alimentos, v. 25, p. 33-36, 1991.

MIRANDA, M. P.; DANTAS, V. P.; DEL CORRAL, F. S. D. Grau alcoólico e níveis de metanol em aguardentes do comércio (no Estado da Bahia). Boletim da Sociedade Brasileira de Ciência e Tecnologia de Alimentos, v. 26, n. 2, p. 104-107, 1992.

Morais, P. B. et al. Characterization and succession of yeast populations associated with spontaneous fermentations during the production of Brazilian sugar cane. World Journal Microbiology and Biotechnology, v. 13, p. 241-243, 1997.

MURTA, A. L. M. et al. Determinação da composição de aguardentes de cana de açúcar por cromatografia gasosa. Archives of Biology and Technology, v. 25, n. 2, p. 221-226, 1982.
NASCIMENTO, R. F. et al. Determination of acids in Brazilian sugar cane spirits and other alcoholic beverages by HRGC-SPE. Chromatographia, v. 48, p.1-7, 1998.

NOVAES, F. V. et al. Curso de extensão em aguardente de cana. Piracicaba: ESALQ/Departamento de Tecnologia Rural, 1974.

NYKANEN, L.; NYKANEN, I. Rum flavor. In: PIGGOTT, J. R. Flavour of distilled beverages: Origin and Development. Flórida: Verlag Chemie International, INC., 1983. p. 49-63.

OLIVEIRA, C. R. et al. Cachaça de Alambique - Manual de Boas Práticas Ambientais e de Produção. Belo Horizonte: SEMAD/ FEAM, 2005. 72 p. (Convênio de Cooperação Técnica - SEAPA/ SEMAD/AMPAQ/FEAM/IMA)

PARANHOS, S. B. Cana-de-açúcar: cultivo e utilização. 2 ed. Campinas: Fundação Cargill, 1987.

Pataro, C. et al. Yeast communities and genetic polymorphism of Saccharomyces cerevisiae strains associated with artisanal fermentation in Brazil. Journal of Applied Microbiology, v. 88, p. 1-9, 2000.

Pataro, C. et al. Physiological characterization of yeasts isolated from artisanal fermentation in an aguardente distillery. Review of Microbiology, v. 29, p. 104-108, 1998.

PINO, J. A. Estudio de los constituyentes volatiles del aguardiente de caña. Alimentaria: Revista de Tecnologia e Higiene de los Alimentos, v. 301, p. 119-122, 1999.

POTTER, N. N. Food Science. Westport: Ani, 1980. 653p.

São Paulo. Associação Brasileira de Bebidas - ABRABE. A cachaça. Disponível em: <http://www.abrabe.org.br/cachaca.php>. Acesso em: 12 Jul. 2007.

SCHWAN, R. F. et al. Microbiology and physiology of cachaça (aguardente) fermentations. Journal of Microbiology, v. 79, p. 89-96, 2001.

SOUZA, L. G.; LLISTÓ, A. M. S. M. Alguns dos componentes do coeficiente não-álcool das aguardentes de cana: Determinação por cromatografia em fase gasosa. Brasil Açucareiro, n. 3, p. 13-16, 1978.

TEJERA, I. F. et al. Determinación de metanol y alcoholes superiores en aguardientes de Orujo gallegos. Alimentaria: Revista de Tecnología e Higiene de los Alimentos, v. 231, p. 57-59, 1992.

VARGAS, E. A.; GLORIA, M. B. Qualidade da aguardente de cana (Saccharum officinarum, L.) produzida, comercializada e/ou engarrafada no Estado de Minas Gerais. Ciência e Tecnologia de Alimentos, v. 15, n. 1, p. 43-46, 1995.

ZENEBON, O.; BADOLATO, E. S. G.; NAGTO, L. A. F. Metanol avaliação da ocorrência de intoxicações causadas pela ingestão de bebidas alcoólicas no estado de São Paulo. Boletim da Sociedade Brasileira de Ciência e Tecnologia de Alimentos, v. 30, n. 1, p. 71-71, 1996.

WINDHOLZ, M. The Merck Index. Rahway: Merck, 1606. p. 1976. 